\title{
Risk Analysis of Auditing Caused by the Development of E-commerce
}

\author{
Zhang Yangyue \\ School of Economics and Management, Nanjing University of Science and Technology, Nanjing 210000, \\ China
}

2383378022@qq.com

Keywords: e-commerce, audit development, internet.

\begin{abstract}
More and more enterprises use e-commerce to carry out business activities. Compared with traditional enterprises, e-commerce enterprises have their own unique characteristics, and thus have different effects on auditing. It expands the scope and the content of the audit, injects new vitality into the audit.However, at the same time it increases the risk of the audit and raises new requirements and challenges in the audit. Auditors should fully consider the particularity of the e-commerce industry when carrying out the audit work. They should not only consider the characteristics of the industry, but also consider the impact of changes in the audit environment, audit content and audit risk.
\end{abstract}

\section{Introduction}

In the 21st century, e-commerce began to get people's attention. Nowadays, with the gradual maturity of Internet technology and the application of related scientific information technology in e-commerce, e-commerce is no longer an activity of buying and selling solely through the Internet. With the gradual maturity of related information technology in e-commerce,e-commerce is no longer an activity of buying and selling solely via the Internet. Instead, it has developed into an Internet-based trading process that integrates information flow, business flow, capital flow and logistics.E-commerce companies is different from the traditional offline businesses. It brings new challenges to audit. In the e-commerce environment, due to changes in the audit scope and audit objects and other factors, the audit risk will inevitably be different. Therefore, it is of great significance to study the change of auditing work caused by e-commerce business.

\section{The General Situation of e-commerce}

E-commerce has been developed for more than 10 years in our country. Now the economic growth in our country is slowing down, however, the entire e-commerce industry is in a thriving state and has become a new growth point of China's economy. Compared with the traditional business activities, e-commerce is flexible and convenient in form and choice, thus greatly improving the efficiency of the enterprise. E-commerce has been deep into all aspects of people’s lives.

\subsection{Technical means are gradually becoming mature}

E-commerce is a kind of commercial activity which utilizes the micro-computer technology and the network communication technology. The upgrading of various technical means and hardware equipments has led to the rapid development of e-commerce in China. A more diversified product information, a more complete logistics and distribution system and a more convenient and safe fund settlement system provide a broad market space for the development of e-commerce.

\subsection{The conversion of people's ideas are gradually changed}

People's shopping philosophy, lifestyle has become more active and open, they pursue cheap products with high quality. Compared with the traditional business, e-commerce has the characteristics of convenient and easy to compare, so people prefer to use the network for 
consumption. Gradual conversion of ideas makes people choose electronic transactions.

\subsection{Related policies give support to e-commerce}

With the support of "Internet +" policy, traditional e-commerce is easier to be transformed. The e-commerce of commodities has been accelerated to upgrade its level and the personal consumption service platform has been innovated constantly. Cross-border e-commerce, rural e-commerce and mobile e-commerce have accelerated their development and e-commerce has ushered in a new opportunities.

\section{New vitality brought by e-commerce to audit}

\subsection{Audit content continues to expand}

First of all, because a series of activities in e-commerce will generate electronic evidence, auditing of electronic evidence will become the most important part of auditing. At the same time, the safety of the network will be included in the scope of auditing, which needs to be evaluated and focused on attention . Computer viruses, hackers, theft and tampering with electronic information all threaten the security of e-commerce businesses.

Second, e-commerce has brought a lot of data accumulated in the computer or cloud storage, it can be transferred when needed. Data is also very easy for auditors to query and use to obtain various reports or make financial analysis. The storage of these large number of data put forward higher requirements to audit work, people need to ensure that the data is accurate and complete, in order to effectively use the data. Auditors need to not only master computer knowledge and application technology, but also check the reliability of computerized systems and enterprise cloud service platforms.

Thirdly, the division of jobs in the traditional mode can not meet the needs of e-commerce accounting and management. Accountants should be given new content and job responsibilities. Auditors need to check whether e-commerce companies have set up relevant positions and responsibilities. Many enterprises in this new area prone to loopholes.

Finally, "free" became the mainstream in the Internet era.E-commerce enterprises attract users through some free services and then find new profit points around these user. Based on this business model, a large amount of sunk cost of initial investment by an enterprise does not immediately bring about a corresponding profit. At this time, how to evaluate the operating performance of an Internet e-commerce enterprise from an audit perspective and how to judge the profitability of an enterprise become new contents that need to be added to the audit.

\subsection{E-commerce changed the environment of the financial audit of the enterprise}

At present, the audit of e-commerce enterprises lacks a perfect legal environment, which also creates some obstacles to the audit work. Because the early development of e-commerce is comprehensive, China's laws on e-commerce are mainly distributed in different departmental law: contract law, tort law, product liability law, consumer protection law, electronic signature law, cyber-security law and some other laws. With the rapid development of e-commerce, our country pays more attention to e-commerce legislation. With the rapid development of e-commerce, the relevant auditing standards in our country have been trying hard to build.

Since the previous audit was a manual review of credentials, statements and other materials, their working environment included corporate financial data, financial accounting and auditing reports, the development of the Internet and the rise of e-commerce makes the intervention of auditing work more diversified. The financial audit of the enterprise is increased from the auditing of the financial accounting information to the supervision of the software users and maintainers. The increase in professional language also makes auditing difficult and diverse. 


\subsection{New data risk appeared in audit}

The new audit risk is mainly manifested in the contradiction between the authenticity and integrity of audit data and the clutter and inaccuracy of big data. The authenticity of the data is a valuable foundation. Even the audited units of the original financial data may be errors. Data obtained from other sources, such as those obtained from search engines and service platforms, need to be effectively screened and validated. Therefore, the auditors in the data collection stage need to establish a risk awareness and know exactly what data is needed, where it is obtained, and whether these data are complete.

Industry diversification will lead to an increase in the number of data types, as well as the contradictions between data and data standardization . Judging from the current status of industry laws and regulations, large-scale audit data will still exist in a variety of non-uniform information status for a very long time and still need to formulate standards that can promote the breadth and depth of data integration. It is necessary to achieve the unity of data integration, but also to ensure that all sectors of the personalized data will not be lost. We need practice to find a solution of how different data analysis methods for different areas of data requirements.

\section{New requirements of auditing put forward by the development of e-commerce}

\subsection{Involve in the development of related systems}

Auditors need to be able to directly participate in the design and development process of the related system software of the e-commerce enterprise. The development of the supervisory system must be conducted in accordance with the standard development rules to ensure that the related system procedures and application controls meet the accounting management needs and achieve the desired quality. At the same time, it also provides auditors with an opportunity to review the system development process and evaluate application controls.

\subsection{Consult an expert}

The business content of E-commerce enterprises is special and innovative, and there are a lot of aspects that require auditors to make career decisions. For example, the article mentioned earlier that e-commerce companies increase the number of users by attracting users for free and then finding new profit points around the users. Due to the fact that Internet users' information is independent of the financial accounting system, based on this business model, the sunk cost caused by a large amount of initial investment of an enterprise can not immediately bring corresponding profits. At this time, how to judge the profitability of an enterprise from the audit point of view become a new problem. This requires a high degree of professional judgment on the part of auditors. We need to focus on the connection between financial information and non-financial information during the audit work, pay attention to the number of web users and the download volume, registration volume and activeness of APP users Degree, retention rate and other non-financial indicators. At the same time, we must adopt a targeted audit plan and audit procedure to judge the rationality and authenticity of the data in terms of logic and trend, and fully recognize the relevant risks of material misstatement. Here we can draw on existing cases or seek help from relevant industry experts to help us make professional judgments to reduce unnecessary miscarriage of justice.

\subsection{Emphasis on internal control}

E-commerce enterprises have stronger peculiarities than traditional industries. In particular, the operating risks of Internet companies are much higher than those in the traditional industries. Their gross profit margin is exceptionally high and their income-cost ratio is poor. Products and services are frequently replaced by new ones and the quality of participants need to be high. The existence of these inherent risks keeps the audit going with the challenges posed by high risks. Therefore, the auditors need to pay special attention to the design of the internal control system, the rationality of the 
formulation and the effectiveness of the implementation so as to determine whether the internal control is credible and effective.

\subsection{Improve the corresponding audit standards}

The purpose of the audit software is to serve the audit work. Therefore, when using the audit software to carry out the work, the application of the software must be combined with the actual situation of the audit work. As for the current enterprise e-commerce business, enterprises should developed for different information systems platforms which is based on different computers and operating environment software. The auditors should use the technology of big data to collect, organize, analyze and process all the data related to the entire business of the audited entity and then output the final audit report, and comprehensively evaluate whether the audited entity effectively uses the financial information system to ensure the safety of the assets. The future of internal audit of its own information technology and data processing capabilities will rapidly increase. In actual operation, enterprises can rely on the strength of technicians and auditors to jointly fulfill the requirements of audit software functions so as to develop more efficient and more suitable audit software.

\section{Conclusions}

E-commerce enterprises have their own uniqueness compared with traditional enterprises, therefore, auditors should take full account of the particularity of e-commerce industry in carrying out audit work. They should consider not only the special core business, but also the characteristics of the industry, the audit environment, the audit content and the changes of audit risk. They need to audit the authenticity of the trading activities of electronic business enterprises, the accuracy of accounting data, also the hardware and software systems of electronic commerce system, and also the security and reliability of entire electronics business system.

\section{References}

[1] Wang snow. E-commerce business audit risk and prevention problems - A Case Study of Dingdong, China Academy of Financial Sciences, 2016

[2] Yang Xiaohen. Analysis of the impact of e-commerce on the audit, Accounting Research, 2016 (06)

[3] Zhang Lidia. Analysis of audit risk in e - commerce environment, E-commerce, 2015 (04) 